\title{
Intestinal parasite communities of six sympatric lemur species at Kirindy Forest, Madagascar
}

\author{
Andrea Springer ${ }^{1, \mathrm{a}}$ and Peter M. Kappeler ${ }^{1,2}$ \\ ${ }^{1}$ Behavioral Ecology and Sociobiology Unit, German Primate Center, Kellnerweg 4, \\ 37077 Göttingen, Germany \\ ${ }^{2}$ Department of Sociobiology/Anthropology, University of Göttingen, Kellnerweg 6, \\ 37077 Göttingen, Germany \\ ${ }^{\mathrm{a}}$ current address: Institute for Parasitology, Centre for Infection Medicine, University of Veterinary Medicine \\ Hannover, Buenteweg 17, 30559 Hanover, Germany \\ Correspondence to: Andrea Springer (andrea.springer@tiho-hannover.de)
}

Received: 24 May 2016 - Revised: 22 August 2016 - Accepted: 26 August 2016 - Published: 7 September 2016

\begin{abstract}
Intestinal parasites impact host health, survival and reproductive success and therefore exert selective pressures on hosts' ecology and behavior. Thus, characterizing and comparing the parasitic fauna of different wildlife hosts sharing the same habitat can provide insights into the mechanisms underlying variation in parasitism, as well as the role of parasites as possible conservation threats. Several host traits have been proposed to generate differences in parasite diversity among different host species, including phylogeny, host body mass, host longevity, diet, and differences in ranging and social behavior. Here, we provide an overview of intestinal helminths and protozoa detected by fecal microscopy in six sympatric lemur species in Kirindy Forest, western Madagascar. The described patterns indicate that host phylogeny and diet may play an important role in shaping intestinal parasite assemblages in this system, as the closely related, omnivorous cheirogaleids showed the strongest overlap in parasite communities. No indication was found for an effect of body mass or longevity on parasite species richness. Regarding the effect of sociality, the two group-living lemur species, Propithecus verreauxi and Eulemur rufifrons, harbored directly transmitted parasites at higher prevalence than solitary foragers, but not at higher diversity. Effects of season and sex on parasite prevalence confirm the results of previous studies, with higher prevalence in the energetically demanding dry season and a male bias in parasitism. We highlight the opportunities of exploring the parasitic fauna of wildlife from a community ecology and evolutionary perspective, and identify prospects for future research on lemur parasitism.
\end{abstract}

\section{Introduction}

Parasites affect host survival and reproduction and thus constitute an important selective force shaping host physiology, ecology and behavior (Coltman et al., 1999; Nunn and Altizer, 2006; Wood and Johnson, 2015). Specifically, intestinal helminths and protozoa may cause reduced energy uptake, pathological damage and decrease their hosts' reproductive success (Hudson et al., 1992, 1998; Delahay et al., 1995; Hillegass et al., 2010). In addition, they impact the host's immune system and alter gut microbial communities (Kreisinger et al., 2015; Reynolds et al., 2015), potentially in- creasing host susceptibility to bacteria or viruses (Cox, 2001; Ezenwa and Jolles, 2015).

Thus, natural selection should favor mechanisms that reduce exploitation by parasites, whereas parasites evolve mechanisms to circumvent these defense strategies and to secure their ecological niches in this evolutionary arms race. As a consequence, considerable differences in parasite species richness may be generated between different host species. Understanding the factors contributing to this variation in parasite diversity is relevant for fundamental questions in ecology (Poulin, 2004) as well as for species conservation (Kamiya et al., 2014). Host switching, intra-host speciation 
and loss of parasites over evolutionary time are the principal mechanisms involved, which can be influenced by host ecological characteristics like body size, longevity, diet, substrate use and social organization (Poulin, 2004). Furthermore, parasites may co-speciate with their hosts so that common ancestry is an additional important determinant of shared parasite communities between related species (Poulin, 2004). However, empirical support for the role of these factors is mixed and their relative importance is not well understood (Poulin, 2004; Kamiya et al., 2014; Morand, 2015). We therefore first discuss these factors in more detail.

First, because hosts are regarded as insular habitats for their parasites, it has been proposed that larger-bodied hosts provide more ecological niches for parasites and should therefore harbor a richer parasitic fauna (Kuris et al., 1980; Poulin, 1995; Gregory et al., 1996). Evidence for a correlation between host body size and intestinal parasite species richness has, for example, been found in tropical freshwater fish (Guégan et al., 1992) and ungulates (Ezenwa et al., 2006). In several meta-analyses across mammals, however, body mass was only a significant predictor of parasite richness if host phylogeny was not controlled for (Poulin, 2004). Likewise, in a meta-analysis across primates, body mass was only positively correlated with parasite richness in non-phylogenetic models (Vitone et al., 2004). Therefore, it appears that larger bodied mammals do harbor richer parasitic faunas, but this pattern may be explained mainly by inheritance of ancestral parasites through phylogeny (Poulin, 2004).

Second, longer-lived hosts may experience more transmission events throughout their lifetime and are therefore expected to harbor more parasite species (Morand and Harvey, 2000). However, if parasites contribute to host mortality, a negative association between parasite species richness and longevity seems more likely (Cooper et al., 2012). Additionally, longevity is often positively correlated with host body size, making it difficult to distinguish between these two factors (Poulin, 2004). Controlling for host body mass, Morand and Harvey (2000) found a negative correlation between longevity and parasite species richness across mammals. The same pattern was found in ungulates (Ezenwa et al., 2006; Cooper et al., 2012), whereas no association between longevity and parasite species richness was found in carnivores and primates (Cooper et al., 2012). Thus, evidence for a positive association between longevity and parasite species richness is weak and it seems more likely that parasite-induced mortality has selected for short life histories and fast reproduction in some taxa (Cooper et al., 2012).

Third, many helminths with complex life cycles are transmitted via ingestion of intermediate hosts (Guégan and Kennedy, 1993; Vitone et al., 2004). Host diet should therefore have a strong impact on parasite communities. Carnivorous and insectivorous mammals are expected to harbor more indirectly transmitted parasites relative to herbivorous species. In a study across primates, no support for this pat- tern was found, however (Vitone et al., 2004). Until now, diet as a predictor of parasite richness has been examined in too few comparative studies to allow drawing general conclusions across taxa (Kamiya et al., 2014).

Fourth, ranging behavior can influence exposure to fecalorally transmitted parasites by mediating contact with feces (Freeland, 1980; Hart, 1990). More intensive ranging should lead to an increased probability of contact with fecally contaminated substrates, and indeed ranging intensity correlates with helminth richness in African ungulates (Ezenwa, 2004) and primates (Nunn and Dokey, 2006). Likewise, in carnivores, rodents and lagomorphs home range size was found to correlate negatively with helminth richness (Bordes et al., 2009), lending support to the fecal exposure hypothesis. In this context, arboreality has also been evoked as a parasite avoidance strategy, limiting contact with infectious parasite stages present in soil (Nunn et al., 2003; Loudon and Sauther, 2013). However, the only comparative study we are aware of that explicitly tested the influence of this behavioral trait on parasite species richness failed to find a significant effect (Nunn et al., 2003). Therefore, this hypothesis needs additional testing in future studies.

Finally, epidemiological theory predicts that transmission of parasites increases with animal density and, thus, represents one of the major disadvantages of gregariousness (Alexander, 1974; Anderson and May, 1982; Anderson et al., 1986; McCallum et al., 2001). Consequently, gregarious hosts should harbor more parasites than solitary species, and species richness should increase with group size. Indeed, an association of gregariousness with parasite diversity has been found in fish (Ranta, 1992), and gregarious African ungulates display both an increase in parasite prevalence and infection intensity as compared to solitary species (Ezenwa, 2004). Furthermore, a significant relationship between host density and parasite species richness has been found across primates (Nunn et al., 2003). However, a meta-analysis including a wide range of host species from mammals to insects revealed that effect sizes of group size on parasite species richness are generally low, except for animals living in large aggregations (Rifkin et al., 2012). In summary, there is overall support for an association between parasite risk and a gregarious lifestyle, but this relationship varies considerably across taxa (Rifkin et al., 2012).

Here, we examine the intestinal parasite communities of six sympatric lemur species in Kirindy Forest, western Madagascar. To our knowledge, this is the first systematic study comparing intestinal parasite communities of more than two sympatric lemur species. Although the number of studies investigating lemur parasitism has recently increased (e.g., Clough, 2010; Rasambainarivo et al., 2013; Larsen et al., 2016), knowledge on the parasitic fauna of these threatened primates still remains comparatively limited. The host species studied here share the same habitat and are thus theoretically exposed to the same set of parasites, but they differ in their degree of phylogenetic relatedness, body mass, 
Table 1. Characteristics of six lemur species inhabiting Kirindy Forest, Madagascar.

\begin{tabular}{|c|c|c|c|c|c|c|c|}
\hline Species & Family & Body mass & Life span & Diet & $\begin{array}{l}\text { Activity } \\
\text { pattern }\end{array}$ & $\begin{array}{l}\text { Social } \\
\text { organization }\end{array}$ & References \\
\hline $\begin{array}{l}\text { Microcebus } \\
\text { berthae }\end{array}$ & Cheirogaleidae & $22-49 \mathrm{~g}$ & $\begin{array}{l}\text { unknown, } \\
\text { probably similar to } \\
\text { M. murinus }\end{array}$ & $\begin{array}{l}\text { omnivorous, } \\
\text { narrow feeding } \\
\text { niche }\end{array}$ & nocturnal & dispersed groups & $\begin{array}{l}\text { Schülke and Ostner (2005), } \\
\text { Dammhahn and Kappeler } \\
\text { (2008) }\end{array}$ \\
\hline $\begin{array}{l}\text { Microcebus } \\
\text { murinus }\end{array}$ & Cheirogaleidae & $35-110 \mathrm{~g}$ & $\begin{array}{l}\text { mean } 2-3 \text { years, } \\
\text { up to } 11\end{array}$ & $\begin{array}{l}\text { omnivorous, broad } \\
\text { feeding niche }\end{array}$ & nocturnal & dispersed groups & $\begin{array}{l}\text { Schülke and Ostner (2005), } \\
\text { Dammhahn and Kappeler } \\
\text { (2008), Hämäläinen et al. } \\
\text { (2014) }\end{array}$ \\
\hline $\begin{array}{l}\text { Cheirogaleus } \\
\text { medius }\end{array}$ & Cheirogaleidae & $80-270 \mathrm{~g}$ & $\begin{array}{l}>20 \text { years } \\
\text { (in captivity) }\end{array}$ & omnivorous & nocturnal & dispersed pairs & $\begin{array}{l}\text { Fietz and Ganzhorn (1999), } \\
\text { Schülke and Ostner (2005), } \\
\text { Blanco and Zehr (2015) }\end{array}$ \\
\hline $\begin{array}{l}\text { Mirza } \\
\text { coquereli }\end{array}$ & Cheirogaleidae & $270-330 \mathrm{~g}$ & $\begin{array}{l}\text { up to } 17 \text { years } \\
\text { (in captivity) }\end{array}$ & $\begin{array}{l}\text { omnivorous, } \\
\text { including small } \\
\text { vertebrates }\end{array}$ & nocturnal & solitary & $\begin{array}{l}\text { Kappeler (1997), Schülke and } \\
\text { Ostner (2005), Fischer and } \\
\text { Austad (2011) }\end{array}$ \\
\hline $\begin{array}{l}\text { Eulemur } \\
\text { rufifrons }\end{array}$ & Lemuridae & $2.0-2.3 \mathrm{~kg}$ & $>20$ years & $\begin{array}{l}\text { frugivorous, } \\
\text { feeds on animal } \\
\text { matter } \\
\text { occasionally }\end{array}$ & cathemeral & group-living & $\begin{array}{l}\text { Ganzhorn et al. (1999), Donati } \\
\text { et al. (1999), Schnoell and } \\
\text { Fichtel (2013) }\end{array}$ \\
\hline $\begin{array}{l}\text { Propithecus } \\
\text { verreauxi }\end{array}$ & Indriidae & $2.4-4.4 \mathrm{~kg}$ & $>20$ years & $\begin{array}{l}\text { strictly foli- and } \\
\text { frugivorous }\end{array}$ & diurnal & group-living & Kappeler and Fichtel (2012) \\
\hline
\end{tabular}

life histories, diet and social organization, as detailed in Table 1. Thus, variation in patterns of parasitism can be expected based on the hypotheses outlined above.

Four of the species studied (Microcebus murinus, Microcebus berthae, Cheirogaleus medius and Mirza coquereli) belong to the family Cheirogaleidae and exhibit a nocturnal lifestyle. Mouse lemurs (Microcebus spp.) are the smallest extant primates. Their average life span in the wild is 2-3 years, although some gray mouse lemurs (M. murinus) may live for 10 years or more (Hämäläinen et al., 2014). Mouse lemurs usually produce one litter per year (Eberle and Kappeler, 2006). In contrast, fat-tailed dwarf lemurs (Cheirogaleus medius), which are true hibernators, are remarkably long-lived, potentially reaching more than 20 years of age (in captivity, Blanco and Zehr, 2015), but often reproduce only every second year (Lahann and Dausmann, 2010). Coquerel's dwarf lemurs (Mirza coquereli) can live to an age of 17 years in captivity (Fischer and Austad, 2011) and appear to reproduce annually (Kappeler, 1997).

All four cheirogaleid species are omnivores, consuming fruit, plant exudates and invertebrates in varying proportions; Coquerel's dwarf lemurs additionally prey on small vertebrates (Dammhahn and Kappeler, 2014). All cheirogaleids forage solitarily but show differences in their degree of association with conspecifics. The two mouse lemur species (Microcebus spp.) have overlapping home ranges and share sleeping sites with multiple conspecifics, whereas fat-tailed dwarf lemurs live in dispersed pairs but regularly sleep together in the same shelter (Schülke and Ostner, 2005). Only Coquerel's dwarf lemurs can be regarded as truly solitary (Kappeler, 1997).
The other two lemur species examined here, red-fronted lemurs (Lemuridae: Eulemur rufifrons) and Verreaux's sifakas (Indriidae: Propithecus verreauxi), live in multi-male, multi-female groups with male-biased dispersal (Ostner and Kappeler, 2004; Kappeler and Fichtel, 2012). Both species are relatively long-lived, reaching more than 20 years of age in the wild (Kappeler and Fichtel, 2012). Red-fronted lemurs have a cathemeral circadian rhythm, characterized by irregular bouts of activity both during the day and the night (Donati et al., 1999). They are mainly frugivorous but occasionally consume invertebrates and small vertebrates, such as chameleons (Claudia Fichtel, personal communication, 2013; Schnoell and Fichtel, 2013). Red-fronted lemurs spend a significant amount of time on the ground and regularly drink from waterholes (Donati et al., 1999; Scholz and Kappeler, 2003). As members of the Lemuridae, they have a relatively fast life history for their body mass (Ostner and Kappeler, 2004).

The largest lemurs inhabiting Kirindy Forest, Verreaux's sifakas, are strictly diurnal. They are herbivorous, feeding mainly on leaves, but incorporate flowers and fruit into their diet based on seasonal availability (Norscia et al., 2006). Being vertical clingers and leapers, they rarely descend to the ground and do not drink from waterholes, but rather they rely entirely on the water content of their diet and on dew present on trees (Kappeler and Fichtel, 2012). Sifakas are characterized by a slower life history than members of Lemuridae (Richard et al., 1991).

Here, we report intestinal parasite richness and patterns of prevalence for these six lemur species as determined by fecal microscopy. Regarding animal diet, we expected omnivores 
to harbor more parasite species which can be transmitted via intermediate hosts than herbivores. We predicted that the two group-living lemur species would harbor more directly transmitted intestinal parasite species than those with a less cohesive social system, due to more opportunities for transmission events. Because Kirindy Forest is subject to pronounced seasonality, we also compared seasonal variation in parasite prevalence for the three species with the largest sample size, controlling for animal sex. We expected prevalence to be higher during the wet season than during the dry season because of better conditions for parasite survival in the environment during these months.

\section{Methods}

\subsection{Study site}

Kirindy Forest is located at approximately $44^{\circ} 39^{\prime}$ E, $20^{\circ} 03^{\prime} \mathrm{S}$ in the central Menabe region of western Madagascar. It is characterized as dry deciduous forest and subject to pronounced seasonality, with a dry season lasting from April to October and a hot, wet season from November to March (Kappeler and Fichtel, 2012). The study area is part of a field site operated by the German Primate Center (DPZ) since 1993 and is situated within a forestry concession managed by the Centre National de Formation, d'Etudes et de Recherche en Environnement et Foresterie (CNFEREF). Eight lemur species occur in the study area, four of which are classified as endangered (Microcebus berthae, Phaner pallescens, Mirza coquereli, Propithecus verreauxi), one as vulnerable (Lepilemur ruficaudatus), one as near-threatened (Eulemur rufifrons) and only two as least-concern (Microcebus murinus and Cheirogaleus medius, IUCN Red List of Threatened Species, 2016). As part of an ongoing long-term study (Kappeler and Fichtel, 2012), small, nocturnal lemurs are regularly captured in live traps for the purpose of biomedical sampling and individual marking. In addition, several social groups of red-fronted lemurs and Verreaux's sifakas have been habituated to human observers and individually marked with microchips and unique collars.

All necessary research permits were obtained from the respective Malagasy and German authorities (Ministère des Eaux et Forêts of Madagascar; Commission ad hoc Flore et Faune (CAFF) of Madagascar; Centre National de Formation, d'Etudes et de Recherche en Environnement et Foresterie (CNFEREF); The Federal Agency for Nature Conservation of Germany). Regarding animal welfare, we followed the "Code of Best Practices for Field Primatology" of the International Primatological Society.

\subsection{Sampling and sample processing}

Fecal samples from six lemur species were collected in Kirindy Forest from 2006 to 2014 by various researchers. Fecal samples from cheirogaleids were taken during ani- mal handling or from traps following capture in Sherman or Tomahawk live traps from 2010 to 2014 (Hämäläinen et al., 2015b; Rakotoniaina et al., 2016). Fecal samples from $E u$ lemur rufifrons and Propithecus verreauxi were taken during direct observations within 2 min of defecation. All members of eight adjacent study groups of Propithecus verreauxi were sampled during 2013 and 2014 (Springer, 2015), whereas data on parasitism of Eulemur rufifrons were taken from Clough (2010), who sampled all members of four adjacent groups in the years 2006-2007.

Fecal samples were stored in $10 \%$ formalin until analysis. All fecal samples were processed using a modification of the formalin-ethyl acetate sedimentation technique, as described in Clough (2010). This technique is commonly used to recover helminth eggs from formalin-fixed fecal samples of wild primates (Muehlenbein and Watts, 2010; Pebsworth et al., 2012) and results in the sedimentation of eggs, larvae and protozoa on the bottom of the test tube during centrifugation (Ash and Orihel, 1987). Parasite stages were microscopically identified to genus level, if possible, based on morphological criteria following the key in Irwin and Raharison (2009). Seasonal prevalence was calculated as the number of individuals infected with a certain parasite, based on the microscopic results of all available samples per individual from that season.

\subsection{Statistical analyses}

To assess seasonal differences in prevalence, we constructed generalized linear mixed models (GLMMs) with binomial error structure and logit link function for the most prevalent parasites (i.e., with total prevalence across years and seasons $>10 \%$ ) of the three study species which were sampled most intensively. Because sex differences in seasonal prevalence patterns have been reported for M. murinus before (Hämäläinen et al., 2015b), we included animal sex as a fixed factor. Interactions between sex and season were initially included and retained in final models, if significant. In this case, models testing the effect of season were constructed for each sex separately, which can be found in the Supplement (Table S1). To control for repeated sampling of individuals and possible differences between years, animal identity and study year were included as random effects in all models. Significance of models was assessed by comparison with null models containing only random effects using the R-function ANOVA with method set to "Chisq".

\section{Results}

Sixteen unique helminth egg morphotypes and three different protozoan morphotypes were detected in lemur fecal samples. A summary of all morphotypes detected per host species is presented in Table 2. To exclude spurious parasites, we only report morphotypes that were present in more than $1 \%$ of samples from a given species. Microcebus murinus and E. rufifrons harbored the greatest parasite diversity, 


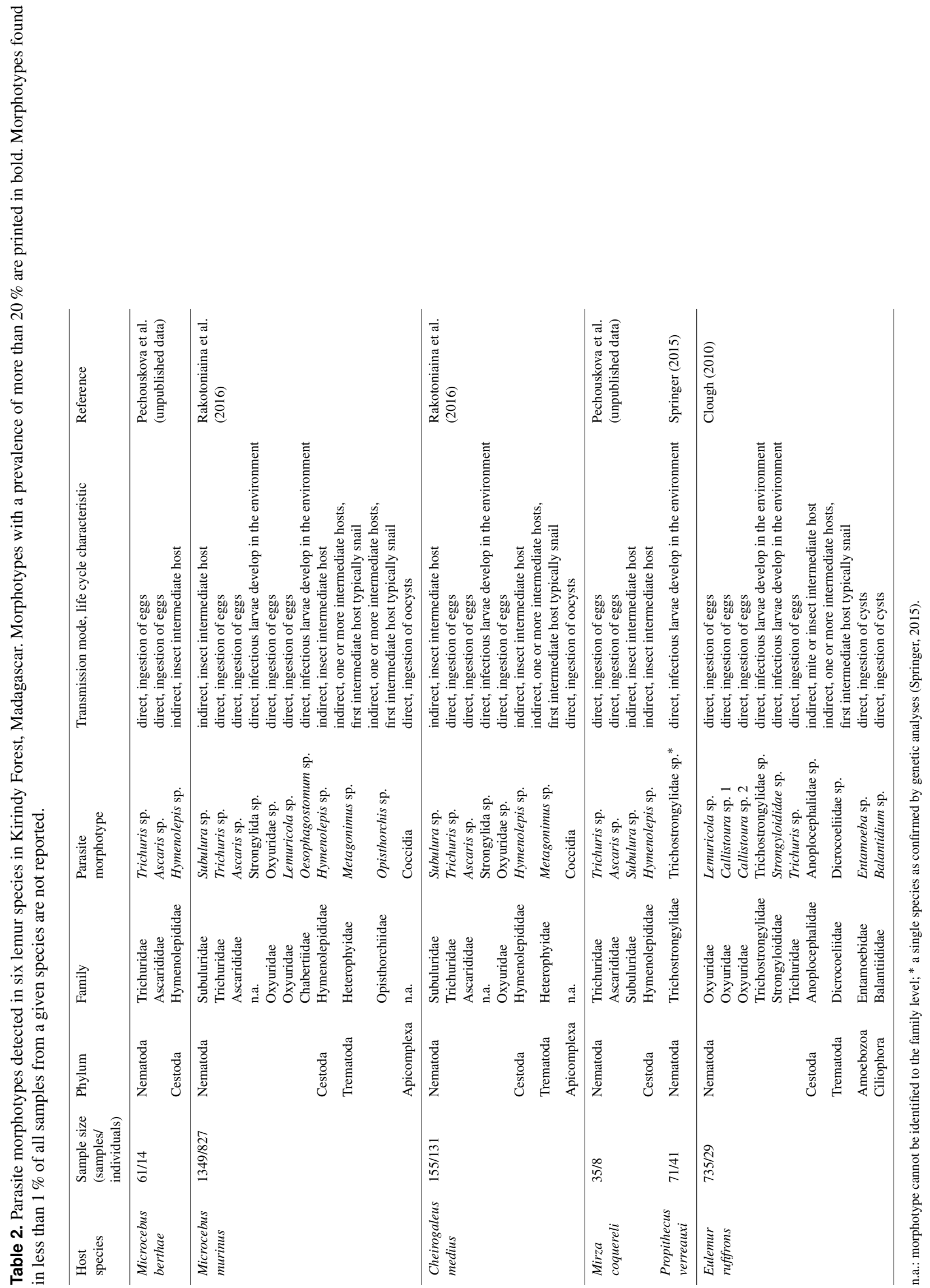




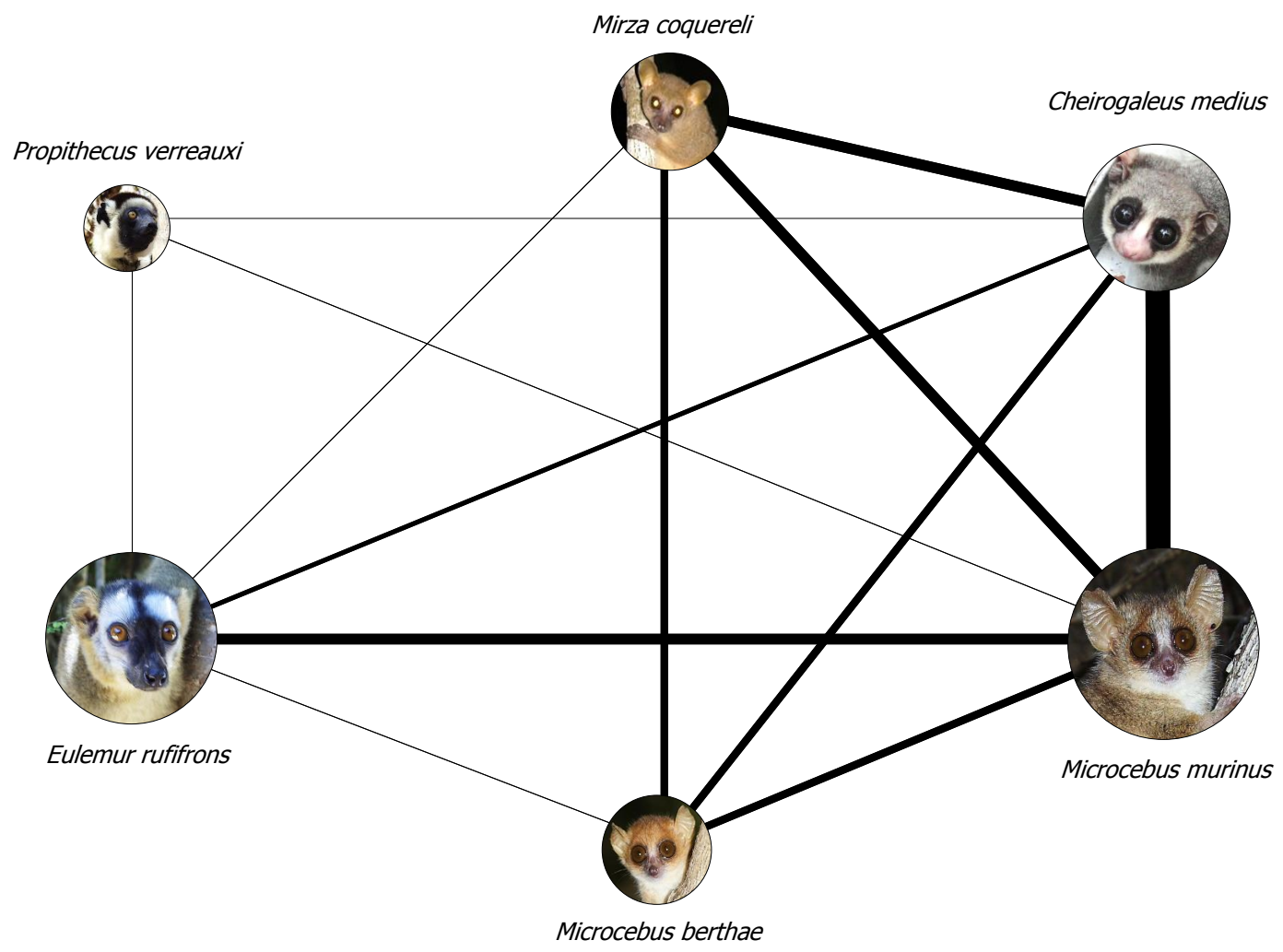

Figure 1. Parasite morphotype sharing network of six sympatric lemur species at Kirindy Forest, Madagascar. Node size corresponds to the number of parasite morphotypes detected in a species, while line width reflects the number of shared morphotypes.

with 11 and 10 distinct morphotypes detected, respectively. However, sample size for M. berthae and M. coquereli was very low so that we probably have not detected the full parasite diversity infecting these species.

In all four cheirogaleids, the most prevalent parasites were Hymenolepis sp. and Subulura sp. (transmitted via intermediate hosts) and Trichuris sp. and Ascaris sp. (directly transmitted nematodes), with the exception that Subulura sp. was not found in $M$. berthae. Cheirogaleids also showed the greatest overlap in their parasite communities (Fig. 1). In fact, all parasites that were found in C. medius, M. berthae or $M$. coquereli also occurred in M. murinus. The most prevalent helminths in Eulemur rufifrons belonged to the families Oxyuridae and Trichostrongylidae, which have direct life cycles. This was also the only species infected with the directly transmitted protozoan parasites Entamoeba sp. and Balantidium sp. Propithecus verreauxi harbored only one intestinal parasite species, belonging to the family Trichostrongylidae (Springer, 2015).

Seasonal prevalence for M. murinus, C. medius and $P$. verreauxi from one exemplary study year (2013) is presented in Table 3. Significant seasonal differences in parasite prevalence were detected in M. murinus and $C$. medius but not in $P$. verreauxi (Table 4). All parasites that showed significant seasonal variation were more prevalent during the dry, lean season than during the wet season. These included both directly (Trichuris sp. and Ascaris sp.) and indirectly ( $\mathrm{Hy}$ menolepis sp. and Subulura sp.) transmitted parasites.

Sex also influenced prevalence patterns in M. murinus and C. medius. Male M. murinus were significantly more often infected with Hymenolepis sp., Subulura sp. and Trichuris sp. and also showed a stronger seasonal variation in infection rate than females (Table S1). No significant effect of season or sex was found for Strongylida infections in M. murinus. Male C. medius harbored significantly more Subulura sp. and Coccidia sp., but no sex-season interaction was found for this species (Table 4).

\section{Discussion}

Characterizing and comparing the parasitic fauna of different wildlife hosts sharing the same habitat can provide insights into the mechanisms underlying variation in parasitism, as well as the role of parasites as possible conservation threats. Here, we provide information on the intestinal parasite communities of six of the eight sympatric lemur species which co-occur in Kirindy Forest, Madagascar. These host species represent three lemur families and include the smallest extant primate species, which is endemic to this area. 
Table 3. Seasonal prevalence of intestinal parasites for three sympatric lemur species at Kirindy Forest, Madagascar, for the year 2013.

\begin{tabular}{|c|c|c|c|c|c|}
\hline Host species & $\begin{array}{l}\text { Total } \\
\text { morphotype } \\
\text { richness }\end{array}$ & Parasite morphotype & $\begin{array}{r}\text { Prevalence } \\
\text { dry season } \\
2013\end{array}$ & $\begin{array}{r}\text { Prevalence } \\
\text { wet season } \\
2013\end{array}$ & $\begin{array}{l}N \text { (animals } \\
\text { sampled) } \\
\text { dry/wet }\end{array}$ \\
\hline Microcebus murinus & 11 & $\begin{array}{l}\text { Hymenolepis sp. } \\
\text { Subulura } \mathrm{sp} . \\
\text { Trichuris sp. } \\
\text { Ascaris sp. } \\
\text { Strongylida sp. } \\
\text { Oxyuridae sp. } \\
\text { Metagonimus } \mathrm{sp} . \\
\text { Lemuricola } \mathrm{sp} . \\
\text { Opisthorchis } \mathrm{sp} . \\
\text { Oesophagostomum } \mathrm{sp} . \\
\text { Coccidia }\end{array}$ & $\begin{array}{r}59.50 \% \\
53.06 \% \\
23.67 \% \\
20.00 \% \\
17.96 \% \\
7.76 \% \\
2.04 \% \\
0.82 \% \\
0.41 \% \\
0.00 \% \\
3.27 \%\end{array}$ & $\begin{array}{r}37.36 \% \\
29.12 \% \\
1.10 \% \\
1.10 \% \\
14.29 \% \\
1.65 \% \\
0.00 \% \\
0.00 \% \\
0.00 \% \\
0.55 \% \\
5.49 \%\end{array}$ & $245 / 182$ \\
\hline Cheirogaleus medius & 8 & $\begin{array}{l}\text { Subulura sp. } \\
\text { Hymenolepis sp. } \\
\text { Trichuris sp. } \\
\text { Ascaris sp. } \\
\text { Oxyuridae sp. } \\
\text { Strongylida sp. } \\
\text { Metagonimus sp. } \\
\text { Coccidia }\end{array}$ & $\begin{array}{r}49.35 \% \\
48.05 \% \\
18.18 \% \\
13.00 \% \\
7.79 \% \\
7.79 \% \\
2.60 \% \\
2.60 \%\end{array}$ & $\begin{array}{l}8.33 \% \\
4.17 \% \\
0.00 \% \\
4.17 \% \\
0.00 \% \\
4.17 \% \\
4.17 \% \\
8.33 \%\end{array}$ & $77 / 24$ \\
\hline Propithecus verreauxi & 1 & Trichostrongylidae sp. & $97.00 \%$ & $89.50 \%$ & $33 / 38$ \\
\hline
\end{tabular}

\subsection{Patterns of morphotype sharing}

We detected a total of 16 different intestinal parasite morphotypes based on fecal microscopy. The most intensively sampled host species, the gray mouse lemur (M. murinus), harbored 11 different parasite morphotypes. Eight of these also occurred in fat-tailed dwarf lemurs (C. medius). A strong overlap in the parasite communities of $M$. murinus and $C$. medius has been reported before (Schwensow et al., 2010). We show that the most common parasite morphotypes found in these two species, Trichuris sp., Ascaris sp. and Hymenolepis sp., also occur at high prevalence in the two other sympatric cheirogaleids, $M$. berthae and $M$. coquereli. Of these most common parasites of cheirogaleids, only Trichuris sp. occurred in the more distantly related E. rufifrons, and none in $P$. verreauxi. The fact that overlap in parasite communities was highest within the same host taxonomic family indicates that shared ancestry may be an important factor underlying parasite assemblages in these lemurs.

It has to be kept in mind that sample size was very limited for M. berthae and M. coquereli, as these species generally occur at low densities and are rarely captured. Thus, we have probably only detected their most prevalent parasite morphotypes, and it is possible that they harbor more parasites at lower prevalence, which they may or may not share with sympatric species. In addition, sample storage may adversely affect egg recovery rates as some morphotypes degrade more quickly in formalin than others (e.g., Lynsdale et al., 2015) so that some infections may have gone unnoticed. However, all samples were stored in formalin and the duration of storage did not differ systematically among host species. Furthermore, we can only report morphotypes here, as species differentiation via genetic analyses was not possible in this study. Thus, whether or not the same morphotypes from different host species actually represent the same parasite species, or just closely related species, remains a subject for future research. At present, species identification based on genotyping is further hampered by the lack of publicly available reference sequences for lemur parasites.

\subsection{Influence of ecological and behavioral characteristics on infection patterns}

The observed infection patterns indicate that, in addition to phylogeny, host diet may play a role in shaping parasite assemblages in this system. As expected, more indirectly transmitted parasites occurred in the omnivorous cheirogaleids as compared to the two herbivorous species. All cheirogaleids studied here supplement their diet with insects. While the exact life cycles and transmission pathways of lemur parasites are unknown (Irwin and Raharison, 2009), evidence from similar parasites of domestic species suggests that insects serve as intermediate hosts for two of the most prevalent parasites in cheirogaleids, namely Subulura sp. and $H y$ menolepis sp. In contrast, strictly herbivorous $P$. verreauxi showed the lowest intestinal parasite diversity, harboring 


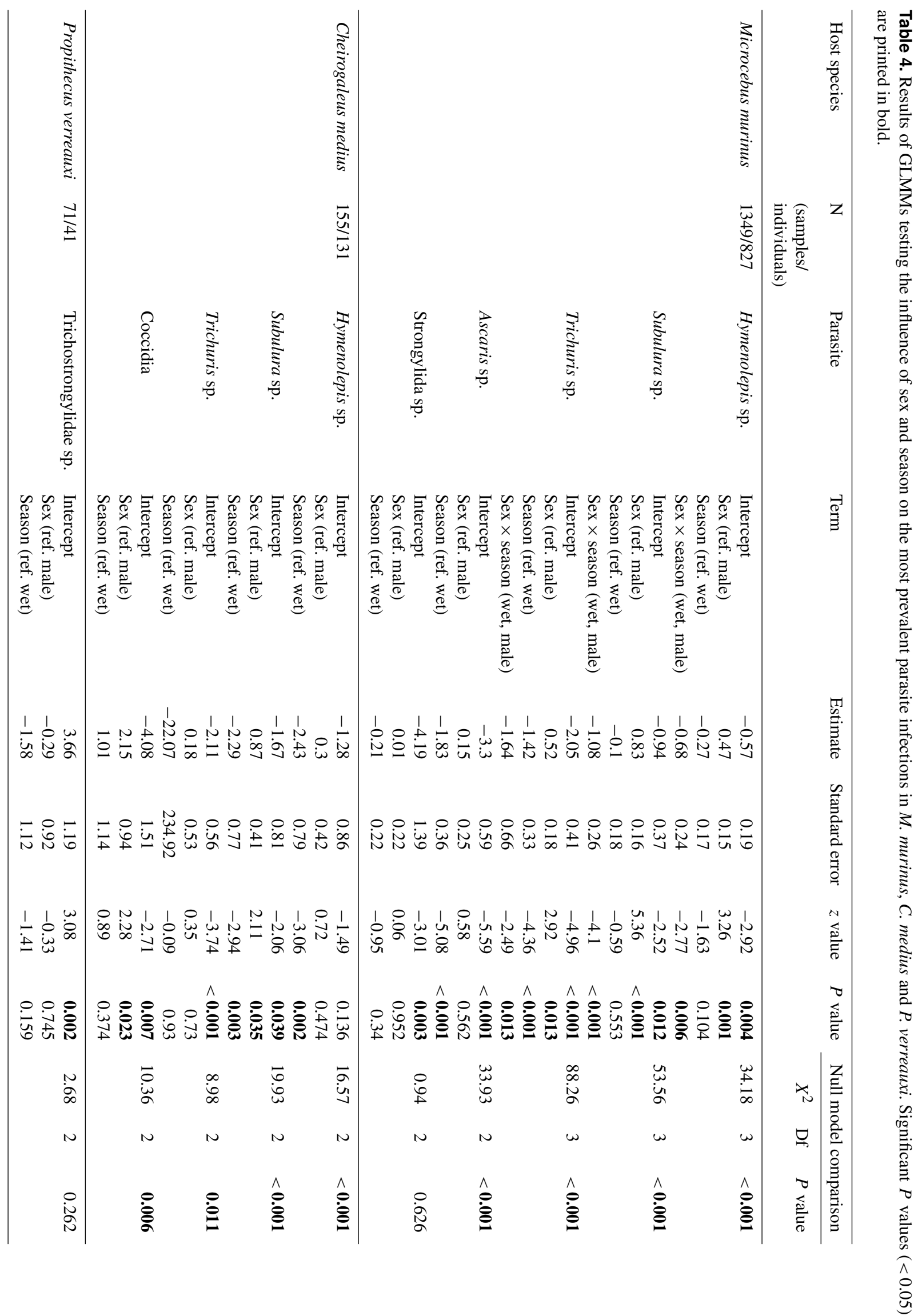


only one directly transmitted parasite (Trichostrongylidae sp.). Low species diversity of intestinal parasites in $P$. verreauxi has been reported before, also at other study sites in Madagascar (Loudon and Sauther, 2013; Rambeloson et al., 2014).

Only 2 of 10 parasites harbored by the mainly frugivorous E. rufifrons are indirectly transmitted (Dicrocoeliidae sp. and Anoplocephalidae sp.), and these occurred at low prevalence compared to directly transmitted parasites (Clough, 2010). Furthermore, the second intermediate hosts of Dicrocoeliidae and Anoplocephalidae are usually arthropods present in the vegetation, e.g., oribatid mites in the case of Anoplocephalidae (Denegri, 1993), which are accidentally ingested by the definitive host, which explains the presence of these indirectly transmitted parasites in herbivorous animals.

We found no indication for host body mass, longevity or social system as a determinant of intestinal parasite richness in this community. Contrary to the hypotheses that parasite richness should increase with host body mass and age, one of the smallest and shortest-lived species, M. murinus, harbored the highest diversity of intestinal parasites, while the largest species, $P$. verreauxi, which is also long-lived, harbored the smallest diversity. As detailed above, host phylogeny and diet may be the main drivers of this pattern. In a meta-analysis across primates, body mass was only a significant predictor of parasite richness in models that did not account for host phylogeny, while host life history was not associated with any measure of parasite species richness in primates (Vitone et al., 2004).

While both Vitone et al. (2004) and Nunn et al. (2003) report a positive association between animal density and parasite richness, we found no clear pattern regarding the influence of social system on infection patterns. Contrary to our prediction, cheirogaleids, which live solitarily or in dispersed social systems, did not harbor fewer directly transmitted parasites than the two group-living species in terms of species diversity. However, prevalence of directly transmitted parasites was lower in cheirogaleids than in the two group-living species.

There was a striking difference in intestinal parasite diversity between the two group-living species. As mentioned above, $P$. verreauxi harbored only one intestinal parasite, whereas 10 different morphotypes were found in E. rufifrons. While both species live in multi-male, multi-female groups, they show other behavioral differences which may account for this disparity. Propithecus verreauxi rarely descend to the ground and do not drink from waterholes, which may limit contact with environmental parasite stages, whereas $E$. rufifrons spend a considerable amount of time on the ground and regularly drink from waterholes. Nonetheless, prevalence of Trichostrongylidae sp. in $P$. verreauxi was around $90 \%$, and this nematode relies on larval development in the environment to become infectious. Active host-seeking behavior and nictation, i.e., raising of the body in response to olfactory cues, may aid the infectious larvae of this parasite to cling to the hosts' fur during limited ground contact events, and facilitate their spread through the population via direct animal-to-animal contact and grooming (Lee, 2002; MacIntosh et al., 2012; Springer, 2015).

\subsection{Influence of season and sex on prevalence}

We investigated the influence of season and sex on infection status with the most prevalent parasites in a subset of three species, for which a sufficient sample size was available. We found statistically significant effects of season on infection patterns in M. murinus and C. medius but not in P. verreauxi. Regarding E. rufifrons, Clough et al. (2010) found no significant seasonal differences in infection status with the five most prevalent parasites infecting this host.

All parasites that showed a significant seasonal difference in prevalence (Trichuris sp. and Ascaris sp. in M. murinus and Hymenolepis sp. and Subulura sp. in C. medius) were more prevalent during the dry season than during the wet season. This runs contrary to our prediction which was based on the fact that environmental parasite stages usually survive better in moist and warm conditions (e.g., Banks et al., 1990; Besier and Dunsmore, 1993; Ramos et al., 2013). This prediction was supported by higher prevalence of intestinal helminths in the wet as compared to the dry season in chimpanzees (Huffman et al., 1997) and African ungulates (Turner and Getz, 2010), for example. Here, higher prevalence in the dry season may reflect increased host susceptibility to infection rather than increased exposure. The dry season in Kirindy Forest is accompanied by energetically demanding conditions for lemurs due to reduced availability of resources like insects, fruit and leaves, which may reduce body condition (Lewis and Kappeler, 2005; Hämäläinen et al., 2014). In addition, an increase of fecal glucocorticoid metabolites has been found in M. murinus in the dry season, reflecting higher levels of stress (Hämäläinen et al., 2015a). Thus, immune function may be impaired in the dry season due to a trade-off in resource allocation with other body functions (Sheldon and Verhulst, 1996; Martin et al., 2008) and/or due to the immunosuppressive effects of chronically elevated glucocorticoid hormones (Webster Marketon and Glaser, 2008; Cohen et al., 2012).

Furthermore, both $M$. murinus and $C$. medius showed a male bias in parasitism, with males generally having a higher prevalence. In addition, M. murinus males showed a stronger effect of season on infection rates than females. These results confirm those of Hämäläinen et al. (2015b), who reported consistently higher prevalence of the most common parasites in male M. murinus relative to females in the dry season. A male bias in parasitism is common in many mammals and birds and has been attributed to immunosuppressive effects of male sex hormones (Klein, 2004; Hoby et al., 2006) as well as to behavioral differences between males and females (VanderWaal et al., 2013; Hämäläinen et al., 2015b) and differences in body mass (Morand et al., 2004). 


\subsection{Conclusions and prospects for future research}

Here, we have provided an overview of intestinal helminths and protozoa detected by fecal microscopy in six sympatric lemur species, which is a first step towards exploring the parasitic fauna of these animals from a community ecology and evolutionary perspective. The described patterns indicate that host phylogeny and diet may play an important role in shaping intestinal parasite assemblages in this system, whereas no indication was found for an effect of body mass or longevity. Regarding the effect of sociality, group-living lemurs harbored directly transmitted parasites at higher prevalence than solitary foragers but not at higher diversity. Effects of season and sex on parasite prevalence confirm the results of previous studies, with higher prevalence in the energetically demanding dry season and a male bias in parasitism.

Despite these important insights, many gaps in our knowledge still remain, e.g., regarding delimitation of cryptic species with the same egg morphotype, parasite life cycles, pathogenic potential and fitness consequences. While sampling of M. berthae and M. coquereli needs to be intensified in the future, two lemur species, Lepilemur ruficaudatus and Phaner pallescens, could not be included in this study at all. These species are nocturnal and, in contrast to the four cheirogaleids, difficult to trap (Schülke and Kappeler, 2003; Zinner et al., 2003). Sampling of fresh feces during direct observations at night is equally challenging. Despite these difficulties, sampling should be attempted, as including these species would add further information with regard to the influence of ecological characteristics on parasite assemblages. For example, like $P$. verreauxi, both species are predominantly folivorous, rarely descend to the ground and lead a rather solitary life in dispersed pairs, which may result in little diversity of intestinal parasites or low prevalence.

Madagascar is considered a hotspot of biodiversity and lemurs are regarded as the most threatened group of mammals globally, due to intense habitat destruction and human encroachment (Schwitzer et al., 2014). However, information on lemur parasites still remains limited despite their potential relevance for lemur conservation. To date, the pathogenic potential of lemur parasites can only be inferred from related, better studied parasites of domestic animals. For many species, the exact life cycles and location of the different parasite stages within the host remain unknown (Irwin and Raharison, 2009). Necropsies of wild lemurs have been conducted only rarely, as animals are rarely found dead, e.g., due to high predation pressure. Nonetheless, there is a need to identify which parasites can be potentially more harmful than others to evaluate their impact on fitness and their conservation relevance.

Studying natural variation in parasitism may also shed light on which lemur species may be most at risk of acquiring introduced parasites. For example, the zoonotic protozoan parasite Cryptosporidium sp., which is capable of causing severe pathologies in captive lemurs (Charles-Smith et al.,
2010), has been detected in two of four lemur species sampled in a rainforest setting in eastern Madagascar (Rasambainarivo et al., 2013). Among the species found positive was the local mouse lemur species, Microcebus rufus, which was also shown to harbor potentially diarrhea-associated viruses and pathogenic enterobacteria in two other studies (Bublitz et al., 2014; Zohdy et al., 2015). Mouse lemurs also harbored the greatest intestinal parasite diversity in our study, indicating that ecological and behavioral characteristics may make members of this genus more likely to pick up introduced diseases than other lemurs.

Despite the remaining gaps in our knowledge, this longterm field study continues to provide the unique opportunity of studying host-parasite relationships in a natural setting. For example, repeated sampling of individuals over their life span allows addressing questions related to immunosenescence and fitness outcomes. Hämäläinen et al. (2015b) were able to show a within-individual decline in parasite infections of aging gray mouse lemurs, for example, indicating acquired immunity by older animals rather than immunosenescence. Finally, comparison of the parasitic faunas of the same species assemblages in multiple study areas, which differ for example in the amount of anthropogenic disturbance, can shed light on the impact of environmental factors on animal health and fitness. This information is crucial to assess the coping capacity of populations in light of increasing habitat disturbance and climate change.

\section{Data availability}

All raw data have been stored in the data bank of the Behavioral Ecology and Sociobiology Unit of the German Primate Center and are available upon request.

\section{The Supplement related to this article is available online at doi:10.5194/pb-3-51-2016-supplement.}

Acknowledgements. We thank the team of the Kirindy field station, especially Rodin Rasoloarison and Léonard Razafimanantsoa, and the Malagasy Ministère de l'Environnement et des Eaux et Forêts, the Département Biologie Animale de l'Université d'Antananarivo, and the Centre National de Formation, d'Etudes et de Recherche en Environnement et Foresterie for supporting and authorizing our long-term research in Kirindy. Tiana Andrianjanahary, Mamy Razafindrasamba and Jean-Pierre Ratolojanahary assisted in animal capture and sample collection. The authors thank the technicians at the Institut Pasteur of Madagascar for analyzing a part of the samples and Josué H. Rakotoniaina, Eva Pechouskova and Cornelia Kraus for sharing unpublished data. Peter M. Kappeler is particularly grateful to Franz-Josef Kaup for decades of shared passionate disgust of ticks and wishes "Allzeit Glück auf!" for his retirement. This research was funded by the Deutsche Forschungsgemeinschaft (Ka 1082/29-1) and the German Primate Center and has profited from discussions in the research 
group "Sociality and Health in Primates" (FOR 2136).

Edited by: K. Mätz-Rensing

Reviewed by: one anonymous referee

\section{References}

Alexander, R. D.: The evolution of social behavior, Annu. Rev. Ecol. Syst., 5, 325-383, doi:10.1146/annurev.es.05.110174.001545, 1974.

Anderson, R. M. and May, R. M.: Directly transmitted infectious diseases: control by vaccination, Science, 215, 1053-1060, doi:10.1126/science.7063839, 1982.

Anderson, R. M., May, R. M., Joysey, K., Mollison, D., Conway, G. R., Cartwell, R., Thompson, H. V., and Dixon, B.: The invasion, persistence and spread of infectious diseases within animal and plant communities [and discussion], Philos. T. Roy. Soc. Lond. B, 314, 533-570, doi:10.1098/rstb.1986.0072, 1986.

Ash, L. R. and Orihel, T. C.: Parasites, a guide to laboratory procedures and identification, American Society of Clinical Pathologists, Chicago, 328 pp., 1987.

Banks, D. J. D., Singh, R., Barger, I. A., Pratap, B., and Le Jambre, L. F.: Development and survival of infective larvae of Haemonchus contortus and Trichostrongylus colubriformis on pasture in a tropical environment, Int. J. Parasitol., 20, 155-160, doi:10.1016/0020-7519(90)90095-5, 1990.

Besier, R. B., and Dunsmore, J. D.: The ecology of Haemonchus contortus in a winter rainfall region in Australia: the development of eggs to infective larvae, Vet. Parasitol., 45, 275-292, doi:10.1016/0304-4017(93)90082-X, 1993.

Blanco, M. B. and Zehr, S. M.: Striking longevity in a hibernating lemur, J. Zool., 296, 177-188, doi:10.1111/jzo.12230, 2015.

Bordes, F., Morand, S., Kelt, D. A., and Van Vuren, D. H.: Home range and parasite diversity in mammals, Am. Nat., 173, 467474, 2009.

Charles-Smith, L. E., Cowen, P., and Schopler, R.: Environmental and physiological factors contributing to outbreaks of Cryptosporidium in Coquerel's Sifaka (Propithecus coquereli) at the Duke Lemur Center: 1999-2007, J. Zoo Wildl. Med., 41, 438444, doi:10.1638/2009-0160.1, 2010.

Clough, D.: Gastro-intestinal parasites of red-fronted lemurs in Kirindy Forest, Western Madagascar, J. Parasitol., 96, 245-251, doi:10.1645/ge-2258.1, 2010.

Clough, D., Heistermann, M., and Kappeler, P. M.: Host intrinsic determinants and potential consequences of parasite infection in free-ranging red-fronted lemurs (Eulemur fulvus rufus), Am. J. Phys. Anthropol., 142, 441-452, doi:10.1002/ajpa.21243, 2010.

Cohen, S., Janicki-Deverts, D., Doyle, W. J., Miller, G. E., Frank, E., Rabin, B. S., and Turner, R. B.: Chronic stress, glucocorticoid receptor resistance, inflammation, and disease risk, P. Natl. Acad. Sci. USA, 109, 5995-5999, doi:10.1073/pnas.1118355109, 2012.

Coltman, D. W., Pilkington, J. G., Smith, J. A., and Pemberton, J. M.: Parasite-mediated selection against inbred soay sheep in a free-living, island population, Evolution, 53, 1259-1267, doi:10.2307/2640828, 1999.

Cooper, N., Kamilar, J. M., and Nunn, C. L.: Host longevity and parasite species richness in mammals, PLoS ONE, 7, e42190, doi:10.1371/journal.pone.0042190, 2012.
Cox, F. E. G.: Concomitant infections, parasites and immune responses, Parasitology, 122, S23-S38, doi:10.1017/S003118200001698X, 2001.

Dammhahn, M. and Kappeler, P.: Comparative feeding ecology of sympatric Microcebus berthae and M. murinus, Int. J. Primatol, 29, 1567-1589, doi:10.1007/s10764-008-9312-3, 2008.

Dammhahn, M. and Kappeler, P. M.: Stable isotope analyses reveal dense trophic species packing and clear niche differentiation in a Malagasy primate community, Am. J. Phys. Anthropol., 153, 249-259, doi:10.1002/ajpa.22426, 2014.

Delahay, R. J., Speakman, J. R., and Moss, R.: The energetic consequences of parasitism: effects of a developing infection of Trichostrongylus tenuis (Nematoda) on red grouse (Lagopus lagopus scoticus) energy balance, body weight and condition, Parasitology, 110, 473-482, doi:10.1017/S0031182000064817, 1995.

Denegri, G. M.: Review of oribatid mites as intermediate hosts of tapeworms of the Anoplocephalidae, Exp. Appl. Acarol., 17, 567-580, doi:10.1007/bf00053486, 1993.

Donati, G., Lunardini, A., and Kappeler, P. M.: Cathemeral activity of red-fronted brown lemurs (Eulemur fulvus rufus) in the Kirindy Forest/CFPF, in: New Directions in Lemur Studies, edited by: Rakotosamimanana, B., Rasamimanana, H., Ganzhorn, J. U., and Goodman, S. M., Springer US, Boston, MA, 119-137, 1999.

Eberle, M. and Kappeler, P. M.: Family insurance: kin selection and cooperative breeding in a solitary primate (Microcebus murinus), Behav. Ecol. Sociobiol., 60, 582-588, doi:10.1007/s00265-0060203-3, 2006.

Ezenwa, V. O.: Host social behavior and parasitic infection: a multifactorial approach, Behav. Ecol., 15, 446-454, doi:10.1093/beheco/arh028, 2004.

Ezenwa, V. O. and Jolles, A. E.: Opposite effects of anthelmintic treatment on microbial infection at individual versus population scales, Science, 347, 175-177, doi:10.1126/science.1261714, 2015.

Ezenwa, V. O., Price, S. A., Altizer, S., Vitone, N. D., and Cook, K. C.: Host traits and parasite species richness in even and odd-toed hoofed mammals, Artiodactyla and Perissodactyla, Oikos, 115, 526-536, doi:10.1111/j.2006.0030-1299.15186.x, 2006.

Fietz, J. and Ganzhorn, U. J.: Feeding ecology of the hibernating primate Cheirogaleus medius: how does it get so fat?, Oecologia, 121, 157-164, doi:10.1007/s004420050917, 1999.

Fischer, K. E. and Austad, S. N.: The development of small primate models for aging research, Inst. Labor. Animal Res. J., 52, 7888, doi:10.1093/ilar.52.1.78, 2011.

Freeland, W. J.: Mangabey (Cerocebus albigena) movement patterns in relation to food availability and fecal contamination, Ecology, 61, 1297-1303, 1980.

Ganzhorn, J. U., Wright, P. Ñ., and Ratsimbazafy, J.: Primate communities: Madagascar, in: Primate communities, edited by: Fleagle, J. G., Janson, C. H., and Reed, K., Cambridge University Press, Cambridge, UK, 75-89, 1999

Gregory, R., Keymer, A., and Harvey, P.: Helminth parasite richness among vertebrates, Biodivers. Conserv., 5, 985-997, 1996.

Guégan, J.-F. and Kennedy, C. R.: Maximum local helminth parasite community richness in British freshwater fish: a test of the colonization time hypothesis, Parasitology, 106, 91-100, doi:10.1017/S0031182000074862, 1993. 
Guégan, J.-F., Lambert, A., Lévêque, C., Combes, C., and Euzet, L.: Can host body size explain the parasite species richness in tropical freshwater fishes?, Oecologia, 90, 197-204, 1992.

Hämäläinen, A., Dammhahn, M., Aujard, F., Eberle, M., Hardy, I., Kappeler, P. M., Perret, M., Schliehe-Diecks, S., and Kraus, C.: Senescence or selective disappearance? Age trajectories of body mass in wild and captive populations of a small-bodied primate, P. Roy. Soc. B, 281, 20140830, doi:10.1098/rspb.2014.0830, 2014.

Hämäläinen, A., Heistermann, M., and Kraus, C.: The stress of growing old: sex- and season-specific effects of age on allostatic load in wild grey mouse lemurs, Oecologia, 178, 1063-1075, doi:10.1007/s00442-015-3297-3, 2015a.

Hämäläinen, A., Raharivololona, B., Ravoniarimbinina, P., and Kraus, C.: Host sex and age influence endoparasite burdens in the gray mouse lemur, Front. Zool, 12, 25, $2015 \mathrm{~b}$.

Hart, B. L.: Behavioral adaptations to pathogens and parasites: Five strategies, Neurosci. Biobehav. Rev., 14, 273-294, doi:10.1016/s0149-7634(05)80038-7, 1990.

Hillegass, M. A., Waterman, J. M., and Roth, J. D.: Parasite removal increases reproductive success in a social African ground squirrel, Behav. Ecol., 21, 696-700, doi:10.1093/beheco/arq041, 2010.

Hoby, S., Schwarzenberger, F., Doherr, M. G., Robert, N., and Walzer, C.: Steroid hormone related male biased parasitism in chamois, Rupicapra rupicapra rupicapra, Vet. Parasitol., 138, 337-348, doi:10.1016/j.vetpar.2006.01.028, 2006.

Hudson, P. J., Dobson, A. P., and Newborn, D.: Do parasites make prey vulnerable to predation? Red grouse and parasites, J. Anim. Ecol., 61, 681-692, 1992.

Hudson, P. J., Dobson, A. P., and Newborn, D.: Prevention of population cycles by parasite removal, Science, 282, 2256-2258, doi:10.1126/science.282.5397.2256, 1998.

Huffman, M., Gotoh, S., Turner, L., Hamai, M., and Yoshida, K.: Seasonal trends in intestinal nematode infection and medicinal plant use among chimpanzees in the Mahale Mountains, Tanzania, Primates, 38, 111-125, doi:10.1007/BF02382002, 1997.

Irwin, M. T. and Raharison, J.-L.: A review of the endoparasites of the lemurs of Madagascar, Malagasy Nature, 2, 66-93, 2009.

IUCN Red List of Threatened Species: Version 2015-4, http://www. iucnredlist.org, last access: 15 February 2016.

Kamiya, T., O’Dwyer, K., Nakagawa, S., and Poulin, R.: What determines species richness of parasitic organisms? A metaanalysis across animal, plant and fungal hosts, Biol. Rev., 89, 123-134, doi:10.1111/brv.12046, 2014.

Kappeler, M. P.: Intrasexual selection in Mirza coquereli: evidence for scramble competition polygyny in a solitary primate, Behav. Ecol. Sociobiol., 41, 115-127, doi:10.1007/s002650050371, 1997.

Kappeler, P. M. and Fichtel, C.: A 15-year perspective on the social organization and life history of sifaka in Kirindy Forest, in: Long-Term Field Studies of Primates, edited by: Kappeler, P. M. and Watts, D. P., Springer, Berlin, Heidelberg, Germany, 101$121,2012$.

Klein, S. L.: Hormonal and immunological mechanisms mediating sex differences in parasite infection, Parasite Immunol., 26, 247264, doi:10.1111/j.0141-9838.2004.00710.x, 2004.

Kreisinger, J., Bastien, G., Hauffe, H. C., Marchesi, J., and Perkins, S. E.: Interactions between multiple helminths and the gut mi- crobiota in wild rodents, Philos. T. Roy. Soc. B, 370, 20140295 , doi:10.1098/rstb.2014.0295, 2015.

Kuris, A. M., Blaustein, A. R., and Alio, J. J.: Hosts as islands, Am. Nat., 116, 570-586, 1980.

Lahann, P. and Dausmann, K. H.: Live fast, die young: flexibility of life history traits in the fat-tailed dwarf lemur (Cheirogaleus medius), Behav. Ecol. Sociobiol., 65, 381-390, doi:10.1007/s00265-010-1055-4, 2010.

Larsen, P. A., Hayes, C. E., Williams, C. V., Junge, R. E., Razafindramanana, J., Mass, V., Rakotondrainibe, H., and Yoder, A. D.: Blood transcriptomes reveal novel parasitic zoonoses circulating in Madagascar's lemurs, Biol. Lett., 12, 20150829 , doi:10.1098/rsbl.2015.0829, 2016.

Lee, D. L. E.: The biology of nematodes, CRC Press, Taylor \& Francis Group, Boca Raton, FL, 2002.

Lewis, R. J. and Kappeler, P. M.: Seasonality, body condition, and timing of reproduction in Propithecus verreauxi verreauxi in the Kirindy Forest, Am. J. Primatol., 67, 347-364, doi:10.1002/ajp.20187, 2005.

Loudon, J. E. and Sauther, M.: Verreaux's sifaka (Propithecus verreauxi) and ring-tailed lemur (Lemur catta) endoparasitism at the Bezà Mahafaly Special Reserve, Madag. Conserv. Dev., 8, 21$28,2013$.

Lynsdale, C. L., Santos, D. J., Hayward, A. D., Mar, K. U., Htut, W., Aung, H. H., Soe, A. T., and Lummaa, V.: A standardised faecal collection protocol for intestinal helminth egg counts in Asian elephants, Elephas maximus, Int. J. Parasitol. Parasites Wildl., 4, 307-315, doi:10.1016/j.ijppaw.2015.06.001, 2015.

MacIntosh, A. J. J., Jacobs, A., Garcia, C., Shimizu, K., Mouri, K., Huffman, M. A., and Hernandez, A. D.: Monkeys in the middle: Parasite transmission through the social network of a wild primate, Plos One, 7, e51144, doi:10.1371/journal.pone.0051144, 2012.

Martin, L. B., Weil, Z. M., and Nelson, R. J.: Seasonal changes in vertebrate immune activity: mediation by physiological tradeoffs, Philos. T. Roy. Soc. Lond. B, 363, 321-339, 2008.

McCallum, H., Barlow, N., and Hone, J.: How should pathogen transmission be modelled?, Trends Ecol. Evol., 16, 295-300, doi:10.1016/s0169-5347(01)02144-9, 2001.

Morand, S. and Harvey, P. H.: Mammalian metabolism, longevity and parasite species richness, P. Roy. Soc. B, 267, 1999-2003, doi:10.1098/rspb.2000.1241, 2000.

Morand, S., Goüy de Bellocq, J., Stanko, M., and Miklisová, D.: Is sex-biased ectoparasitism related to sexual size dimorphism in small mammals of Central Europe?, Parasitology, 129, 505-510, doi:10.1017/S0031182004005840, 2004.

Morand, S.: (macro-) Evolutionary ecology of parasite diversity: From determinants of parasite species richness to host diversification, Int. J. Parasitol. Parasites Wildl., 4, 80-87, doi:10.1016/j.ijppaw.2015.01.001, 2015.

Muehlenbein, M. and Watts, D.: The costs of dominance: testosterone, cortisol and intestinal parasites in wild male chimpanzees, BioPsychoSocial Medicine, 4, 1-12, doi:10.1186/17510759-4-21, 2010.

Norscia, I., Carrai, V., and Borgognini-Tarli, S. M.: Influence of dry season and food quality and quantity on behavior and feeding strategy of Propithecus verreauxi in Kirindy, Madagascar, Int. J. Primatol., 27, 1001-1022, doi:10.1007/s10764-006-9056$\mathrm{x}, 2006$. 
Nunn, C. L. and Altizer, S.: Infectious diseases in primates: Behaviour, ecology and evolution, Oxford University Press, Oxford, 400 pp., 2006.

Nunn, C. L. and Dokey, A. T.-W.: Ranging patterns and parasitism in primates, Biol. Lett., 2, 351-354, doi:10.1098/rsbl.2006.0485, 2006.

Nunn, C. L., Altizer, S., Jones, K. E., and Sechrest, W.: Comparative tests of parasite species richness in primates, Am. Nat., 162, 597614, 2003.

Ostner, J. and Kappeler, P. M.: Male life history and the unusual adult sex ratios of redfronted lemur, $E$ lemur fulvus rufus, groups, Anim. Behav., 67, 249-259, doi:10.1016/j.anbehav.2003.05.012, 2004.

Pebsworth, P. A., Archer, C. E., Appleton, C. C., and Huffman, M. A.: Parasite transmission risk from geophagic and foraging behavior in chacma baboons, Am. J. Primatol., 74, 940-947, doi:10.1002/ajp.22046, 2012.

Poulin, R.: Phylogeny, ecology, and the richness of parasite communities in vertebrates, Ecol. Monogr., 65, 283-302, doi:10.2307/2937061, 1995.

Poulin, R.: Macroecological patterns of species richness in parasite assemblages, Basic Appl. Ecol., 5, 423-434, doi:10.1016/j.baae.2004.08.003, 2004.

Rakotoniaina, J. H., Kappeler, P. M., Ravoniarimbinina, P., Pechouskova, E., Hämäläinen, A. M., Grass, J., Kirschbaum, C., and Kraus, C.: Does habitat disturbance affect stress, body condition and parasitism in two sympatric lemurs?, Conserv. Physiol., in press, 2016.

Rambeloson, V. R., Razanabolana, J. R. and Kappeler, P. M.: Etude des parasites intestinaux chez Propithecus verreauxi (Grandidier, 1867) avant et après la période de mise-bas, The Newsletter of the Madagascar Section of the IUCN SSC Primate Specialist Group, Göttingen, 61-67, 2014.

Ramos, R. A. N., Giannelli, A., Dantas-Torres, F., Brianti, E., and Otranto, D.: Survival of first-stage larvae of the cat lungworm Troglostrongylus brevior (Strongylida: Crenosomatidae) under different conditions, Exp. Parasitol., 135, 570-572, doi:10.1016/j.exppara.2013.09.009, 2013.

Ranta, E.: Gregariousness versus solitude: another look at parasite faunal richness in Canadian freshwater fishes, Oecologia, 89, 150-152, doi:10.1007/bf00319028, 1992.

Rasambainarivo, F. T., Gillespie, T. R., Wright, P. C., Arsenault, J., Villeneuve, A., and Lair, S.: Survey of Giardia and Cryptosporidium in lemurs from the Ranomafana National Park, Madagascar, J. Wildl. Dis., 49, 741-743, doi:10.7589/2012-10-264, 2013.

Reynolds, L. A., Finlay, B. B., and Maizels, R. M.: Cohabitation in the intestine: Interactions among helminth parasites, bacterial microbiota, and host immunity, J. Immunol., 195, 4059-4066, doi:10.4049/jimmunol.1501432, 2015.

Richard, A. F., Rakotomanga, P., and Schwartz, M.: Demography of Propithecus verreauxi at Beza Mahafaly, Madagascar: Sex ratio, survival, and fertility, 1984-1988, Am. J. Phys. Anthropol., 84, 307-322, doi:10.1002/ajpa.1330840307, 1991.

Rifkin, J. L., Nunn, C. L., and Garamszegi, L. Z.: Do animals living in larger groups experience greater parasitism? A meta-analysis, Am. Nat., 180, 70-82, doi:10.1086/666081, 2012.
Schnoell, A. and Fichtel, C.: A novel feeding behaviour in wild redfronted lemurs (Eulemur rufifrons): depletion of spider nests, Primates, 54, 371-375, doi:10.1007/s10329-013-0356-4, 2013.

Scholz, F. and Kappeler, P. M.: Effects of seasonal water scarcity on the ranging behavior of Eulemur fulvus rufus, Int. J. Primatol, 25, 599-613, doi:10.1023/B:IJOP.0000023577.32587.0b, 2003.

Schülke, O. and Kappeler, P. M.: So near and yet so far: territorial pairs but low cohesion between pair partners in a nocturnal lemur, Phaner furcifer, Anim. Behav., 65, 331-343, doi:10.1006/anbe.2003.2018, 2003.

Schülke, O. and Ostner, J.: Big times for dwarfs: Social organization, sexual selection, and cooperation in the Cheirogaleidae, Evol. Anthropol., 14, 170-185, doi:10.1002/evan.20081, 2005.

Schwensow, N., Dausmann, K., Eberle, M., Fietz, J., and Sommer, S.: Functional associations of similar MHC alleles and shared parasite species in two sympatric lemurs, Infect. Genet. Evol., 10, 662-668, doi:10.1016/j.meegid.2010.03.012, 2010.

Schwitzer, C., Mittermeier, R. A., Johnson, S. E., Donati, G., Irwin, M., Peacock, H., Ratsimbazafy, J., Razafindramanana, J., Louis, E. E., Chikhi, L., Colquhoun, I. C., Tinsman, J., Dolch, R., LaFleur, M., Nash, S., Patel, E., Randrianambinina, B., Rasolofoharivelo, T., and Wright, P. C.: Averting lemur extinctions amid Madagascar's political crisis, Science, 343, 842-843, doi:10.1126/science.1245783, 2014.

Sheldon, B. C. and Verhulst, S.: Ecological immunology: costly parasite defences and trade-offs in evolutionary ecology, Trends Ecol. Evol., 11, 317-321, doi:10.1016/0169-5347(96)10039-2, 1996.

Springer, A.: Patterns of parasitism in wild Verreaux's sifakas (Propithecus verreauxi) at Kirindy Forest, Madagascar: Assessing the role of host behavior, Doctoral dissertation, Veterinary University of Hannover, Hannover, 222 pp., 2015.

Turner, W. C. and Getz, W. M.: Seasonal and demographic factors influencing gastrointestinal parasitism in ungulates of Etosha National Park, J. Wildl. Dis., 46, 1108-1119, 2010.

VanderWaal, K., Atwill, E., Hooper, S., Buckle, K., and McCowan, B.: Network structure and prevalence of Cryptosporidium in Belding's ground squirrels, Behav. Ecol. Sociobiol., 67, 19511959, doi:10.1007/s00265-013-1602-x, 2013.

Vitone, N. D., Altizer, S., and Nunn, C. L.: Body size, diet and sociality influence the species richness of parasitic worms in anthropoid primates, Evol. Ecol. Res., 6, 183-199, 2004.

Webster Marketon, J. I. and Glaser, R.: Stress hormones and immune function, Cell. Immunol., 252, 16-26, doi:10.1016/j.cellimm.2007.09.006, 2008.

Wood, C. L. and Johnson, P. T. J.: A world without parasites: exploring the hidden ecology of infection, Front. Ecol. Environ. 13, 425-434, doi:10.1890/140368, 2015.

Zinner, D., Hilgartner, R. D., Kappeler, P. M., Pietsch, T., and Ganzhorn, J. U.: Social organization of Lepilemur ruficaudatus, Int. J. Primatol., 24, 869-888, doi:10.1023/a:1024684907250, 2003. 